\title{
Realizações do sujeito expletivo em construções com o verbo ter existencial na fala alagoana
}

\author{
Elyne Giselle de Santana Lima Aguiar Vitório \\ Doutoranda em Linguística pelo Programa de \\ Pós-Graduação em Letras e Linguística da \\ Universidade Federal de Alagoas e bolsista da \\ CAPES.
}

Resumo: Neste trabalho, analisamos as construções existenciais formadas com o verbo ter, buscando verificar se há uma tendência ao preenchimento da posição de sujeito na fala alagoana. Para tanto, recorremos à Teoria da Variação e da Mudança Linguística (LABOV, 1972) e utilizamos o programa computacional GOLDVARB X. De acordo com os nossos dados, constatamos que, na comunidade estudada, há uma tendência ao preenchimento da posição do sujeito em construções com ter existencial e que fatores linguísticos e sociais condicionam tal preenchimento.

Palavras-chave: sujeito expletivo; ter existencial; Abstract: In this work, we analyze the existential constructions formed from the verb "ter", trying verify if there exist a propensity to fill the position subject in the alagoana speech. In this way, we appeal to the Language Change and Variation Theory (LABOV, 1972) and we use the software GOLDVARB X. According with our results, in the studied community, there is a inclination to fill the position subject in the constructions that use "ter existencial" and that linguistics factors and social factors play fundamental role in this fill.

Keywords: expletive subject; "ter" existential; spoken language

língua falada 



\section{Introdução}

É sabido que, desde o Latim Clássico, os verbos ter e haver caminham paralelamente e que devido à perda da força expressiva do verbo haver a língua recorreu ao uso de ter, que gradualmente foi substituindo haver em estruturas de posse e em construções de tempos compostos e, atualmente, coocorre com haver em estruturas existenciais (CALLOU; AVELAR, 2000; DUARTE, 2003; DUTRA, 2000; SILVA, 2004; VITÓRIO, 2006, 2008).

As construções existenciais, de acordo com Viotti (1999), possuem as seguintes especificações: uma posição de sujeito vazia; um verbo de conteúdo semântico fraco, incapaz de estabelecer relações temáticas com seu(s) argumento(s); uma coda em que se realiza uma predicação e cujo estatuto sintático é necessário tornar preciso; e a presença bastante geral de elementos dêiticos, usualmente na coda, o que estabelece uma "ancoragem" das sentenças em um campo espaço-temporal.

No entanto, ao analisarmos as realizações dos verbos ter e haver existenciais na fala alagoana (VITÓRIO, em preparação), notamos que, nem sempre, as construções com ter existencial apresentam uma posição de sujeito vazia, mas sim um pronome sujeito expletivo realizado. Duarte (2003) aponta que "seria natural esperar que os sujeitos não referências ou expletivos começassem também a se realizar foneticamente, apresentando nosso sistema um conjunto de estruturas em que tal posição, antes categoricamente vazia, passaria a se mostrar preenchida" (p.124), tendo em vista que o PB está passando por um processo de mudança que envolve o Parâmetro do Sujeito Nulo no sentido de se tornar uma língua de sujeito pleno.

Dessa forma, analisamos as construções existenciais formadas com o verbo ter, com o intuito de verificar a frequência de uso do sujeito expletivo na comunidade de fala alagoana e mostrar que fatores linguísticos e/ou sociais estão condicionando o preenchimento da posição de sujeito, que, teoricamente, seria vazia. Para tanto, partimos do pressuposto de que uma vez implementada 

${ }^{1}$ A coleta e a transcrição
dos dados foram
realizadas por mim
durante o primeiro
semestre de 2010
e faz parte do meu
trabalho de Doutorado
(VITÓRIO, em
preparação). a mudança no sentido de preenchimento dos sujeitos referenciais no $\mathrm{PB}$, o sistema agora caminha no sentido do preenchimento dos sujeitos não-referenciais.

Nosso trabalho está organizado da seguinte forma: na seção 2, apresentamos os pressupostos teóricometodológicos utilizados para a realização deste estudo; na seção 3, apresentamos os resultados obtidos; e na seção 4, procedemos as nossas considerações finais. Nosso objetivo é traçar o perfil sociolinguístico da comunidade de fala alagoana com relação ao uso do sujeito expletivo em construções existenciais formadas com o verbo ter.

\section{Pressupostos teórico-metodológicos}

Para o desenvolvimento deste estudo, recorremos à Teoria da Variação e da Mudança Linguística (LABOV, 1972), que procura descrever e explicar o uso da língua tendo como ponto de partida as interações verbais dos indivíduos em circunstâncias reais de comunicação. Ao aplicarmos a metodologia variacionista, construímos um envelope de variação (TARALLO, 2003), no qual colocamos como variável dependente a presença e a ausência do sujeito expletivo em construções formadas com o verbo ter existencial e como variáveis independentes, atuando como fatores condicionadores, categorias da estrutura linguística, como tipo de pronome, colocação da expressão locativa na sentença e tempo verbal, e categorias da estrutura social, como sexo, faixa etária e escolaridade.

Em seguida, delineamos nossa amostra, que é composta de produções espontâneas de 72 informantes alagoanos, estratificados de acordo com as variáveis sexo, faixa etária e escolaridade, e nosso corpus, que é formado por 725 construções existenciais formadas com o verbo ter. ${ }^{1}$ Após a seleção e a análise dos dados, utilizamos o programa computacional GOLDVARB $\mathrm{X}$, que nos forneceu a análise quantitativa do fenômeno em estudo e selecionou as variáveis escolaridade, faixa etária e tempo verbal como estatisticamente significativas. 


\section{Resultados obtidos}

Buscando analisar se há uma tendência, na fala alagoana, ao uso de um pronome expletivo em construções existenciais formadas com o verbo ter, analisamos um total de 725 construções com ter existencial e obtivemos os percentuais de $15 \%$ de presença do sujeito expletivo e $85 \%$ de ausência do sujeito expletivo, conforme ilustramos no gráfico abaixo.

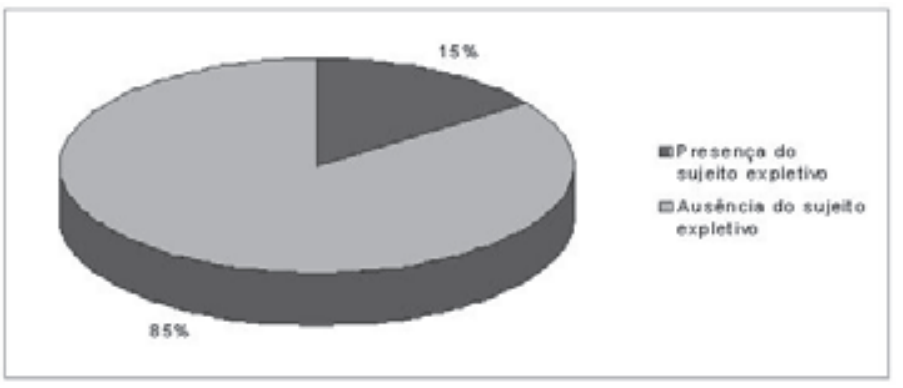

Gráfico 1: Frequência da presença e ausência do sujeito expletivo na fala alagoana

(1) minha rotina de trabalho eu acho legal porque pra mim num é nem rotina porque sempre acontecem coisas diferentes por mais que a gente pleneje assim a gente tem um momento de rotina claro (L72L9080) ${ }^{2}$

(2) tem vários lugares que a pessoa viaja aqui mesmo (L71L9043)

Esses percentuais apontam que, assim como na fala carioca e na fala soteropolitana (MARTINS; CALLOU, 2003), na fala alagoana, também há a presença de um pronome expletivo como sujeito de construções existenciais com o verbo ter, comprovando uma tendência geral na língua do preenchimento da posição do sujeito.

Na comunidade de fala carioca, Duarte (2003) mostra que o percentual de uso de pronomes nessas estruturas sobe de $18 \%$ na amostra de 1980 para 37\% na amostra de 2000, indicando assim um processo de
2 Os códigos apresentados entre parênteses, após os exemplos, referem-se às seguintes orientações do corpus: uma letra $\mathrm{L}$ seguida de um número, que representam um falante específico; e uma letra L seguida de um número, que representam a linha de ocorrência do fenômeno na amostra de fala analisada. 
mudança em curso. Callou e Avelar (2000) também apontam um cenário de mudança em progresso na norma culta carioca, pois da década de 70 para a década de 90 , a frequência de tais construções salta de 3\% para 11\%.

Callou e Avelar (2000) também observam que a frequência de expletivo é maior em falantes mais jovens e quando a expressão locativa aparece anteposta ao verbo existencial. Dessa forma, uma pergunta emerge para possíveis interpretações dos dados: que fatores estão condicionando a realização desse preenchimento na comunidade de fala alagoana?

\subsection{Restrições linguísticas}

Como estratégias utilizadas pelos falantes alagoanos para evitar a posição vazia de sujeito em construções existenciais formadas com o verbo ter, tivemos as realizações dos seguintes pronomes: você, a gente, ele, nós e eu, com um percentual de uso maior dos pronomes você e a gente $-32 \%$ e $30 \%$, respectivamente, conforme gráfico 2:

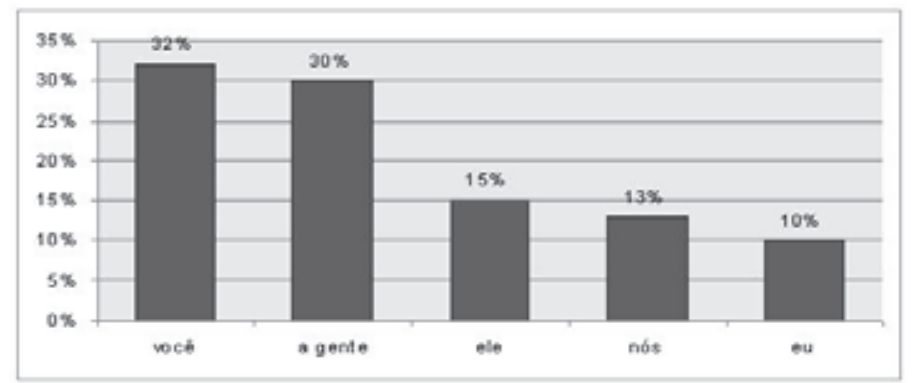

Gráfico 2: Frequência de uso dos pronomes expletivos

(3) é - aí quando você tem um país que tem um desenvolvimento ... (L16L2266)

(4) a gente num tem um policiamento aqui (L14L2061)

(5) na minha opinião o detran tá retraindo - antes ele tinha vários pontos na própria capital pra dá atendimento (L55L6880) 
(6) o governo não traz incentivo pra trazê indústria pra dá imprego ao povo aqui - por isso que (nós) temos altas taxas de criminalidade (L27L3659)

(7) aqui em Maceió o que eu tenho é uma área voltada ao turismo (L30L4033)

Duarte (2003), ao analisar a comunidade de fala carioca, pontua que, na amostra de 1980, só havia ocorrências dos pronomes você e a gente em tais construções existenciais, mas na amostra de 2000, além das formas você e a gente houve também as realizações dos pronomes eu, nós, ele, ela, tu e se.

Nossos dados também apontam que a frequência do expletivo é maior quando a expressão locativa aparece posposta ao verbo existencial, chegando a um percentual de $17 \%$ das realizações. Para os casos em que a expressão locativa é anteposta ao verbo, tivemos um percentual de $12 \%$ e $15 \%$ para construções sem nehuma expressão locativa, conforme ilustramos no gráfico abaixo.

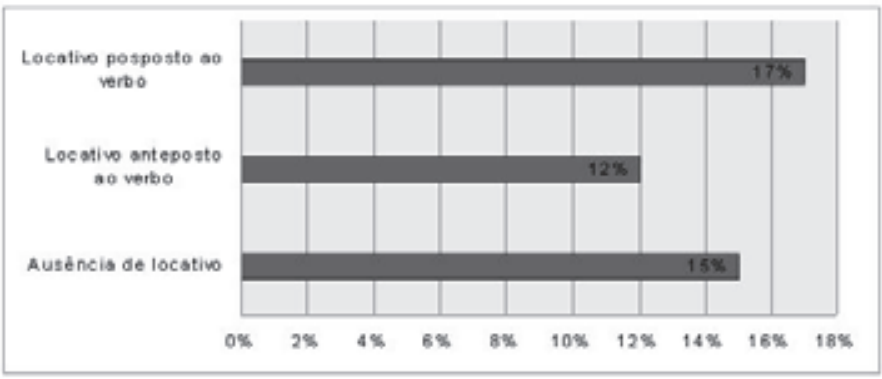

Gráfico 3: Frequência do sujeito expletivo no fator expressão locativa na sentença

(8) a gente nun tem policiamento aqui (L14L2061)

(9) você num tem uma polícia amiga né? (L56L7044)

(10) de um lado você tem regiões muito ricas como a Ponta Verde o Farol (L58L7260)

Quanto à variável tempo verbal, considerada pelo GOLDVARB X como estatisticamente significativa 
neste estudo, verificamos que o tempo expresso com valor de presente é mais favorável a realizações do sujeito expletivo, com um percentual de $16 \%$ versus $8 \%$ para o tempo passado.

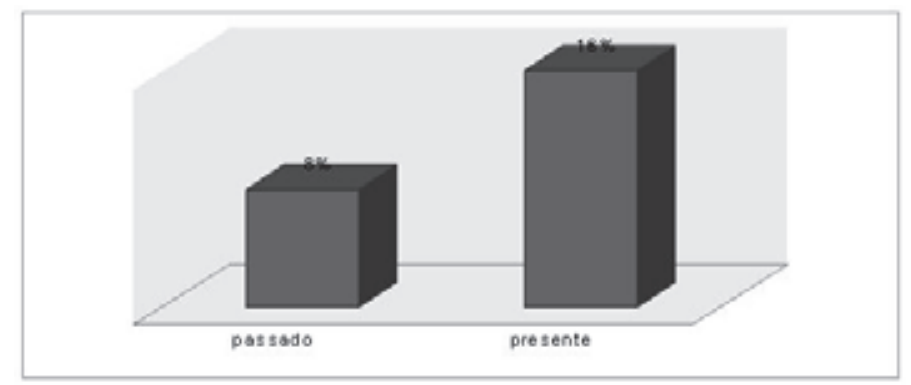

Gráfico 4: Frequência do sujeito expletivo no fator tempo verbal

(11) cara eu acho que a principal causa é:: é a falta de emprego e portunidade pru povo porque não tem educação de qualidade - você não tem educação de qualidade você num tem incentivo (L27L3681)

(12) lá você tinha essa delegacia mais fechô (L53L6595)

Os pesos relativos dos fatores passado e presente confirmam as percentagens apresentadas acima, pois, quando o verbo está no tempo presente, temos um índice de (.53) para as realizações de um sujeito expletivo, enquanto que, no tempo passado, temos um índice de (.35), mostrando que o presente é o tempo verbal que mais favorece à aplicação do expletivo.

Ao cruzarmos as variáveis linguísticas tempo verbal e expressão locativa na sentença, verificamos que, de fato, o preenchimento da posição do sujeito em construções existenciais é mais frequente quando a construção existencial é formada por um verbo no tempo presente e sua expressão locatica está posposta ao verbo, com um percentual de aplicação de $22 \%$, conforme ilustramos no gráfico 5. 


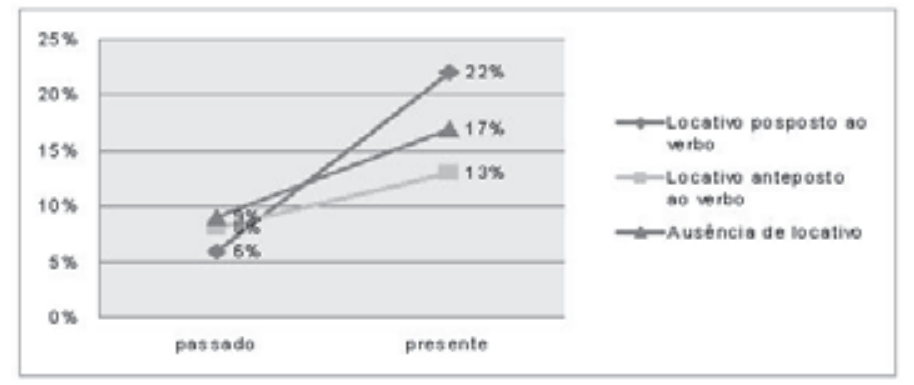

Gráfico 5: Frequência do sujeito expletivo nos fatores tempo verbal e expressão locativa

\subsection{Restrições sociais}

Para a análise dos condicionamentos sociais, levamos em consideração os grupos de fatores sexo, faixa etária e escolaridade e, de acordo com a rodada no GOLDVARB X, apenas as variáveis escolaridade e faixa etária foram estatisticamente significativas no fenômeno em estudo, tendo em vista que as realizações do sujeito expletivo entre homens e mulheres se mostraram dentro da escala de neutralidade, apresentando percentuais de $15 \%$ e $14 \%$, respectivamente.

Para a análise da variável escolaridade, dividimos nossa variável em três fatores, a saber, ensino fundamental (doravante E1), ensino médio (doravante E2) e ensino superior (doravante E3), e constatamos, de acordo com o gráfico abaixo, que são os falantes mais escolarizados que mais utilizam o pronome expletivo, decrescendo o seu percentual de uso à medida que diminui a escolarização dos falantes, indicando assim que quanto maior a escolaridade dos usuários da língua, maior é a frequência do sujeito expletivo na comunidade de fala alagoana. 


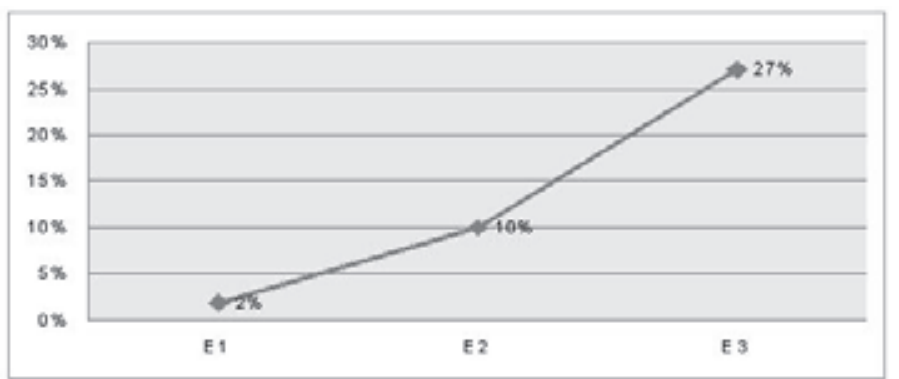

Gráfico 6: Frequência do sujeito expletivo no fator escolaridade

Para a análise da variável faixa etária, dividimos nossa variável em três fatores: faixa etária de falantes com idade entre 15 a 29 anos (doravante F1); faixa etária de falantes com idade entre 30 a 44 anos (doravante F2); e faixa etária de falantes com idade acima de 44 anos (doravente F3), e constatamos que são os falantes da F3 quem mais utilizam o sujeito expletivo com o percentual de $44 \%$ contra $39 \%$ da F2 e $25 \%$ da F1, conforme ilustramos no gráfico abaixo.

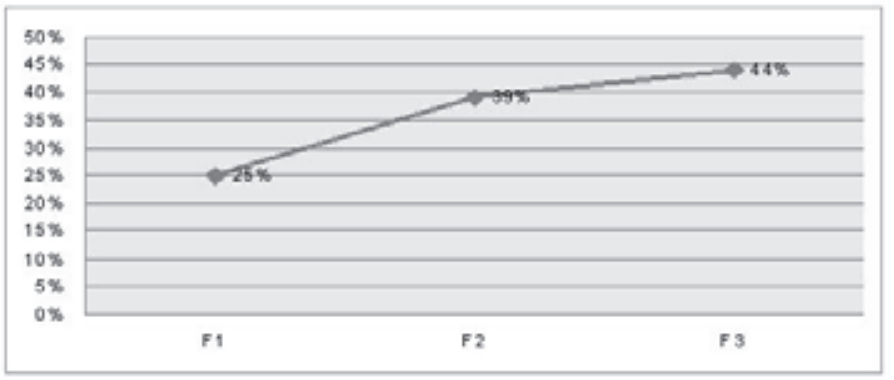

Gráfico 7: Frequência do sujeito expletivo no fator faixa etária

Esses resultados mostram que são os falantes da F3, faixa etária que se caracteriza mais pelo conservadorismo dos padrões sociais e linguísticos (LABOV, 1972), que estão aplicando mais o sujeito expletivo em construções com ter existencial na fala alagoana, contrariando assim os dados de Callou e Avelar (2000), que apontam que, na comunidade de fala carioca, são os falantes mais jovens 
que favorecem tal uso. Nossos dados parecem indicar que, na fala alagoana, o uso do sujeito expletivo em construções existenciais formadas com o verbo ter é tido como uma forma de prestígio, conforme Bailey et al (1992).

Ainda com o intuito de verificar a atuação das variáveis escolaridade e faixa etária nas realizações do fenômeno em estudo, fizemos o cruzamento dessas variáveis e verificamos não só que são os falantes da F3, ou seja, os falantes mais velhos de todos os níveis de escolarização que mais utilizam o sujeito expletivo na fala alagoana, mostrando ser a faixa etária um fator bastante significativo na variação em estudo, como também que o percentual maior de aplicação do sujeito expletivo está entre os falantes mais velhos (F3) e mais escolarizados (E3), com um percentual de 33\%, conforme gráfico 8 abaixo.

O cruzamento entre as variáveis faixa etária e escolaridade parece, de fato, indicar que, na fala alagoana, o uso de um sujeito expletivo em construções existenciais formadas com o verbo ter está sendo visto pelos falantes como uma forma de prestígio na língua, tendo em vista que a utilização do expletivo em tais construções é maior entre os falantes mais velhos e mais escolarizados, ou seja, é maior entre as pessoas que se caracterizam mais pelo conservadorismo dos padrões linguísticos e sociais.

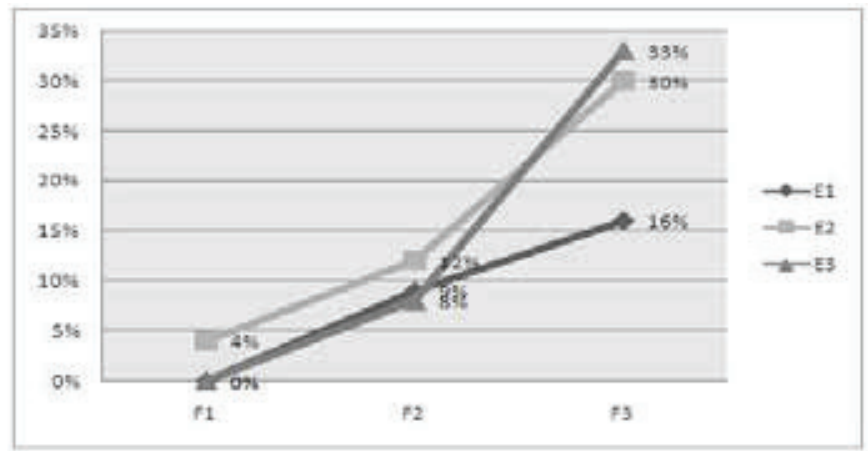

Gráfico 8: Frequência do sujeito expletivo nos fatores faixa etária e escolaridade 
Embora o comportamento linguístico de homens e mulheres tenha se mostrado dentro da escala de neutralidade, indicando, a princípio, que o preenchimento da posição de sujeito em construções com ter existencial na fala alagoana ocorre sem distinção de sexo, decidimos cruzar a variável sexo com as variáveis escolaridade e faixa etária e obtivemos os seguintes resultados:

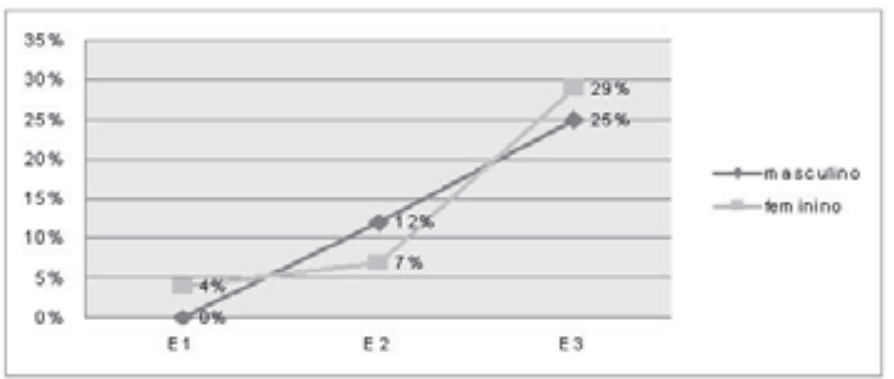

Gráfico 9: Frequência do sujeito expletivo nos fatores sexo e escolaridade

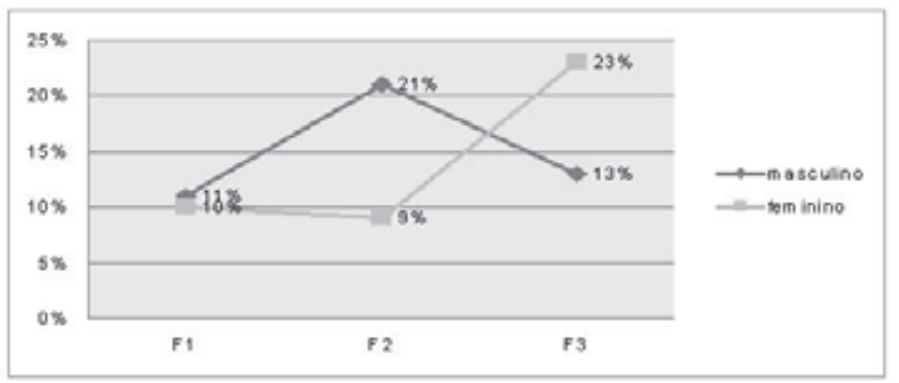

Gráfico 10: Frequência do sujeito expletivo nos fatores sexo e faixa etária

Ao interagirmos as variáveis sexo e escolaridade, segundo o gráfico 9 , notamos que, tanto no sexo masculino quanto no sexo feminino, a presença do sujeito expletivo tende a aumentar com o aumento do nível de escolarização e que são os informantes do sexo feminino quem mais preenchem a posição de sujeito em tais construções, com um percentual de $29 \%$. 
Com relação à interação entre as variáveis sexo e faixa etária, de acordo com o gráfico 10 , verificamos que, nas F2 e F3, homens e mulheres apresentam comportamentos linguísticos diferenciados. Na F2, são os homens que mais preenchem a posição de sujeito expletivo, com um percentual de $21 \%$, já na $\mathrm{F} 3$, são as mulheres que mais aplicam tal preenchimento, com um percentual de $23 \%$ dos casos, diferentemente do que ocorre com os falantes da F1, que apresentam o mesmo comportamento linguístico com relação à utilização do sujeito expletivo.

\section{Conclusão}

Neste artigo, buscamos analisar as construções existenciais formadas com o verbo ter, com o intuito de verificar se há, na fala alagoana, uma tendência ao preenchimento da posição de sujeito, teoricamente vazia, por um pronome expletivo. Através desta observação, constatamos que os falantes alagoanos tendem a preencher tal posição, com um percentual de $15 \%$ e que fatores linguísticos e sociais condicionam tal realização.

De acordo com os nossos dados, o sujeito expletivo é maior representado pelos pronomes você e a gente e ocorre com maior frequência nos seguintes contextos linguísticos: quando a expressão locativa aparece posposta ao verbo ter existencial e em construções com o verbo no tempo presente. Com relação aos fatores sociais, verificamos não só que são os falantes mais escolarizados e mais velhos que mais utilizam o sujeito expletivo, como também que são as mulheres que tendem a preencher mais tal posição.

Dessa forma, desejamos não só ter contribuído para esclarecer as restrições que se correlacionam ao uso do sujeito expletivo em construções com ter existencial na fala alagoana, como também esperamos que os resultados aqui expressos, aliados a outros, possam contribuir para os estudos na área de sociolinguística e auxiliar as pesquisas relacionadas ao Português falado, principalmente ao Português falado no estado de Alagoas. 


\section{Referências}

BAILEY, G.; WIKLE, T.; TILLERY, J.; SAND, L. The apparent time construct. Language Variation and Change, Cambridge, n. 3, p. 241-264, 1992.

CALLOU, D.; AVELAR, J. Sobre ter e haver em construções existenciais: variação e mudança no português do Brasil. Revista Gragoatá, Niterói, n. 9, p. 85-100, 2000.

DUARTE, M. O sujeito expletivo e as construções existenciais. In: RONCARATI, C.; ABRAÇADO, J. (orgs). Português brasileiro: contato lingüístico, heterogeneidade e história. Rio de Janeiro: 7 Letras, 2003, p. 123-131.

DUTRA, C. Ter e haver na norma culta de Salvador. 2000. 186f. Dissertação (Mestrado em Letras) - Universidade Federal da Bahia, Salvador, 2000.

LABOV, W. Sociolinguistic Patters. Philadelphia: University of Pennsylvania Press, 1972.

MARTINS, L.; CALLOU, D. Mudança em tempo aparente e em tempo real: construções ter/haver existenciais. Anais do 5o Encontro do Celsul, Curitiba, p. 820-825, 2003.

SILVA, R. Variação ter/haver na fala pessoense. In: HORA, D (org.). Estudos sociolinguísticos: perfil de uma comunidade. João Pessoa: ILAPEC, 2004, p. 219-234.

TARALLO, F. A pesquisa sociolinguística. São Paulo: Editora Ática, 2003.

VIOTTI, E. A sintaxe das sentenças existenciais do Português do Brasil. 1999. 292f. Tese (Doutorado em Linguística)

- Faculdade de Filosofia, Letras e Ciências Humanas, Universidade de São Paulo. São Paulo, 1999. 
VITORIO, E. Ter/haver existenciais na escrita de alunos de 5a e 6 $6^{a}$ séries do ensino fundamental da cidade de Maracanáu/ CE. 2006. 75f. Monografia (Especialização em Linguística e Ensino do Português). Departamento de Letras Vernáculas, Universidade Federal do Ceará, Fortaleza, 2006.

Ter/haver existenciais na escrita de alunos dos ensinos fundamental e médio da cidade de Maceió/AL. 2008. 119f. Dissertação (Mestrado em Letras e Linguística) - Programa de Pós-Graduação em Letras e Linguística, Universidade Federal de Alagoas. Maceió, 2008.

Ter e haver existenciais na fala alagoana: variação estável ou mudança em progresso? (em preparação). 